José Pedro Sousa

Faculty of Architecture University of Porto Via Panorâmica S/N 4150-755 Porto, PORTUGAL mail@jpsousa.net

Keywords: digital fabrication, CAD/CAM software, computer modelling, computer numerical control milling, $\mathrm{CNC}$
Didactics

\section{Material Customization: Digital Fabrication Workshop at ISCTE/IUL}

Abstract. This paper describes the workshop which took place during the international symposium "Digital Fabrication - a State of Art", which took place at the School of Technology and Architecture ISCTE-IUL, on 15-16September 2011. Its main goal was to introduce a group of about twenty people to the use of digital fabrication in architecture, in a country where these technologies are not yet fully implemented in architecture schools and curricula.

This paper describes the workshop held during the international symposium "Digital Fabrication - a State of Art", which took place at the School of Technology and Architecture ISCTE-IUL, on 15-16September 2011. Its main goal was to introduce a group of about twenty people to the use of digital fabrication in architecture, in a country where these technologies are not yet fully implemented in architecture schools and curricula. Thus, the workshop gathered an international, heterogeneous group of participants, ranging from students with no experience in $3 \mathrm{D}$ modeling to young professionals with skills in parametric design with Grasshopper. For this initiative, the school invited three Portuguese companies to support it. At the technological level, Ouplan installed a 3-axis CNC milling machine. At the material level, Amorim provided pure cork agglomerate (black) and compound cork agglomerate (white) boards, while Investwood supplied Valchromat panels in different colors. The timeframe for the workshop was very short. In total, two afternoons sessions were planned to offer the participants an experience of a continuous process of digital design (CAD) and fabrication (CAM). All these human, technological, material and time parameters defined the workshop conditions (fig. 1).

The starting point consisted in a brief introduction to the use of digital design and manufacturing technologies in architecture. An increasing geometric freedom and the possibility for engaging serial variation logics of production were highlighted as two relevant digital opportunities that have been shaping many of the most relevant contemporary buildings. ${ }^{1}$ In relation with the workshop, the use of CNC milling fabrication was presented in detail as a very versatile process for material customization in architecture. Through such technology, it is possible to execute both $2 \mathrm{D}$ (e.g., contour cutting) and 3D subtractive fabrication operations (e.g., surface milling) through the moving action of a spindle tool. Complementarily, the nature and properties of the testing materials were described and illustrated. As a brief remark, cork products are lightweight, ecological materials that can perform several functions at once. Known as good thermal and acoustic insulation material, pure cork granulate is a $100 \%$ natural material. It results from a thermal process that provokes the volume expansion and selfagglomeration of the granules against the walls of an autoclave without any artificial bonding substance. Overcoming its conventional hidden application as a wall insulation material, it has started being used as an exterior material for building facades since Álvaro Siza built the Portuguese Pavilion at the EXPO 2000 in Hannover. From then on, many buildings have explored such possibilities with success. ${ }^{2}$ In contrast, compound cork implies the use of adhesives to bond together the small triturated granules. 

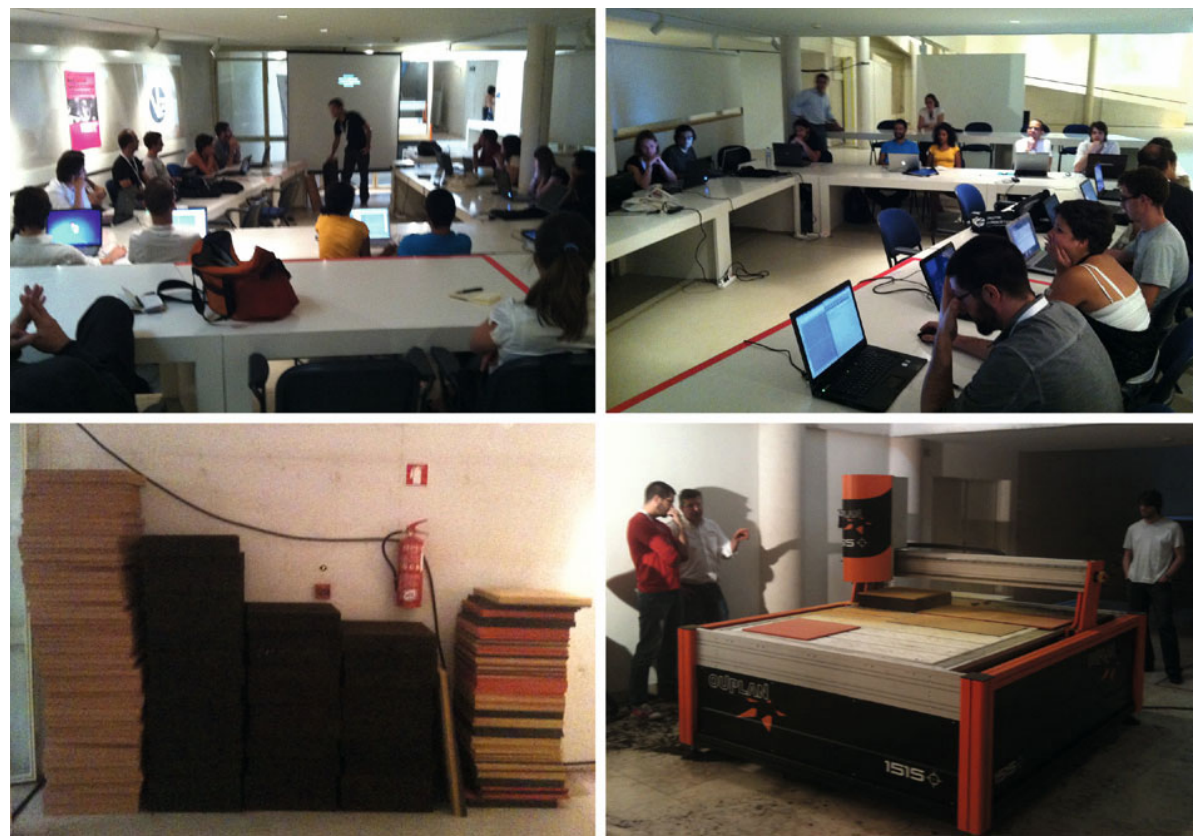

Fig. 1. The workshop environment. Above, images from the studio where the design part took place. Below, images of the available materials (pure cork agglomerate, compound cork agglomerate and Valchromat), and of the fabrication area with the 3 -axis CNC milling machine.

Both spaces were next to each other, which promoted the interaction between the design and fabrication phases

Due to its properties and cost, its conventional application is mostly related to interior and product design. Valchromat can be considered as an evolution of mediumdensity fibreboard (MDF) material, which integrates color pigments throughout its fiber composition. Available in different colors and with a high density, these are highly attractive materials for interior design and furniture applications.

Within this context, three factors were pointed out as the most influential ones for the production of any customized element through $\mathrm{CNC}$ milling processes:

- the design geometry

- the machining instructions

- the material properties

Occurring in the CAD software, the first one sets the overall design geometry (e.g., form, contour, perforations, etc.) of the desired piece by means of $2 \mathrm{D}$ curves and $3 \mathrm{D}$ surfaces. The second factor is concerned with programming the machining instructions with the CAM software. The definition of fabrication parameters like the mill tool and tool path geometries, and the step-over and cutting-depth values, have a profound impact in the final surface texture quality. Finally, the properties of a material composition can add extra qualities to the piece. For instance, by milling layered materials (e.g., plywood) the differences of their variable composition in thickness will show up at the final surface, producing frequently unforeseen and non-designed effects. It is the conscious negotiation of these three factors that can drive architects to achieve a specific material effect by finding an efficient and feasible CAD/CAM strategy to produce it. These multi-level 
intricacies and their design potentiality can be learned from the theoretical investigations and pioneering CAD/CAM projects developed by Bernard Cache and Patrick Beaucé since the mid-1990s. ${ }^{3}$

Given these conditions, the challenge for the workshop was launched: the design and fabrication of a customized 50x50 cm panel by groups of two people. The first step was the selection and definition of the working material out of the three available. The groups could decide between preparing homogeneous blocks made out of layers of a unique material or, instead, heterogeneous blocks made out by gluing different material boards. Then, at the design level, it was proposed to explore a surface generation strategy combining the use of an image editor (e.g., Photoshop) with Rhinoceros. By producing a grayscale picture, the "Heightfield from Image" command in Rhinoceros enables the automatic generation of $3 \mathrm{D}$ digital surfaces by assigning to each grayscale value a specific height on the $z$-axis. This methodology proved to be very intuitive and powerful for two reasons. On the one hand, it allowed CAD beginners to generate interesting forms very quickly. On the other hand, by understanding the logics of graphic-to-surface translation, the careful manipulation of the picture can generate highly sophisticated geometries in a controlled way, which could be very time-consuming to achieve by means of other conventional modeling techniques (e.g., loft, sweep...) (figs. 2 and 3).
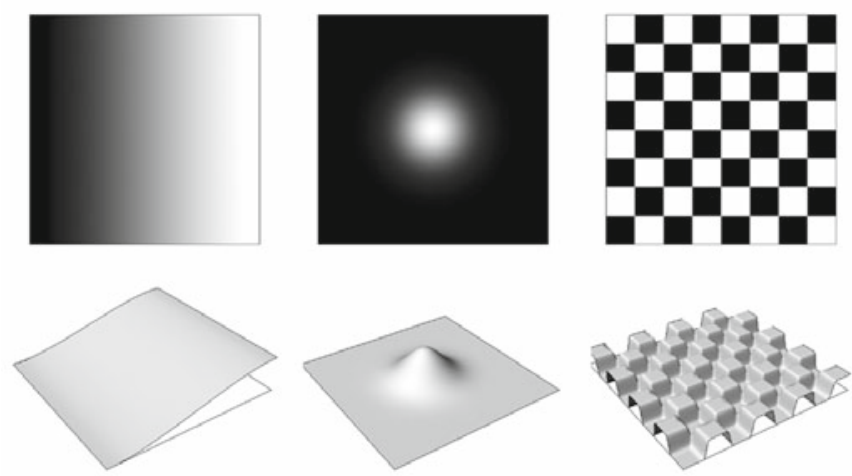

Fig. 2. A few examples of the automatic generation of $3 \mathrm{D}$ surfaces in Rhinoceros from $2 \mathrm{D}$ grayscale pictures. The logic behind this process can be easily understood and its potential of application is very large
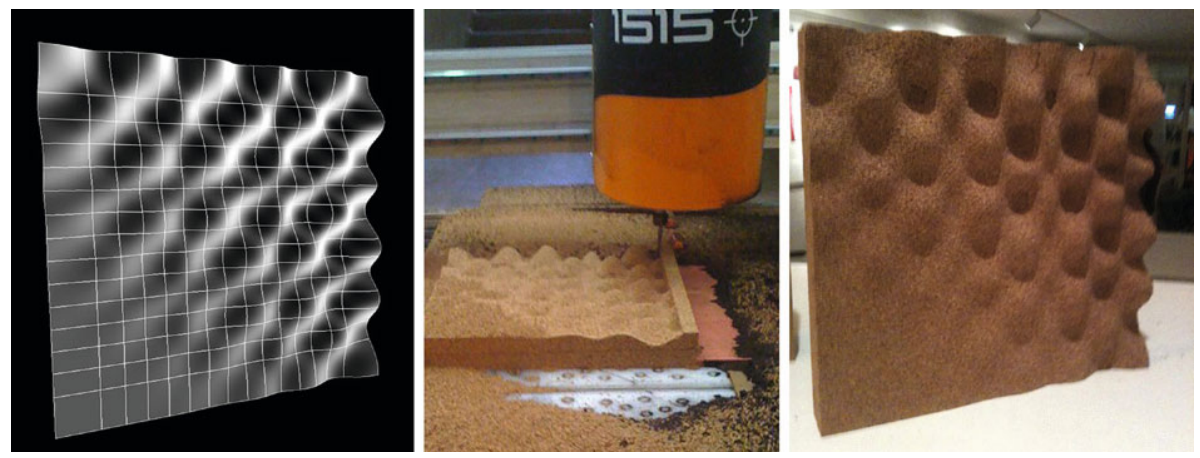

Fig. 3. A custom panel in compound cork, whose design was conceived by using the "Heightfield from Image" function in Rhinoceros 
More experienced participants were allowed to explore alternative design modeling strategies. In one of the works, to control the modeling of a Voronoi pattern for milling, the use of Grasshopper was important to quickly and automatically generate a diagram out of a point cloud (fig. 4).
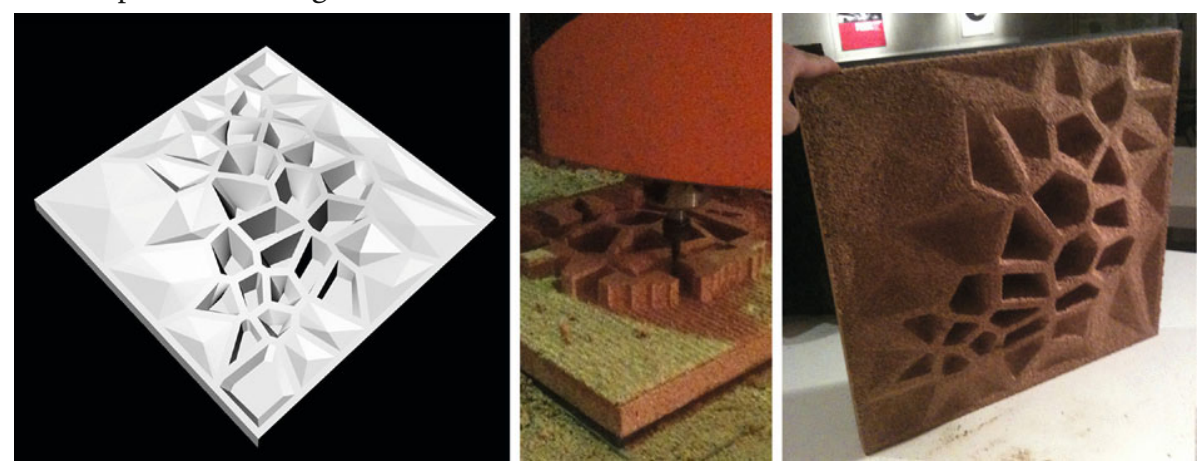

Fig. 4. A custom panel in compound cork, whose design was conceived in Rhinoceros with the help of Grasshopper to control the generation of a Voronoi diagram

During the design process, the groups were encouraged to digitally preview the final result of their intentions by simulating the final aspect of their project. This was tested either through 3D modeling operations (e.g. subtraction of solids and surfaces) or through machining simulation in the CAM software. By doing this, the groups could start sensing how the material consequences at the fabrication level could affect the design intention in a retroactive way. After digitally previewing the effects, some of them went back to adjust their design geometry to achieve better results. Unlike traditional linear processes, these feedback loops between design and fabrication are a major opportunity for creativity arising from the CAD/CAM environment. If there had been more time available for the workshop, the fabrication of some parts would have been desirable.

To allow every group to have an experience of digital fabrication, a maximum machining time of thirty minutes was assigned to each. As soon as the first ones got their design project ready, the $\mathrm{CNC}$ machine started working. The technician from Ouplan took care of the CAM programming and the material set up on the machine, following the participants machining interests. Almost all works were finished within the assigned timeframe for fabrication. Due to some geometric delicacy and/or the need to remove large amounts of material, some works required more time to be finished. Nevertheless, such incompleteness was not a problem at all, as the successful materialization of the design intention was proved with the partial fabricated part. These same works were also important to raise some critical discussion about the use of CNC milling machine technologies in architecture. Unlike traditional manual or mechanical processes, the key cost issue in digital fabrication is not so much dictated by the geometric complexity of the work but, instead, by the fabrication time consumed. These digital conditions set up a new paradigm shift in the logics of production. For instance, when trying to fit the project in the budget, architects may adjust the fabrication parameters (e.g., increasing the step-over values) to achieve a faster fabrication time and consequently, a reduction of cost. Such decisions at the fabrication level prevent them from quitting or simplifying their design geometry in the CAD file and can sometimes bring surprising effects to the project. 
An overall look at the panels produced in the workshop can make evident two different tendencies (fig. 5).
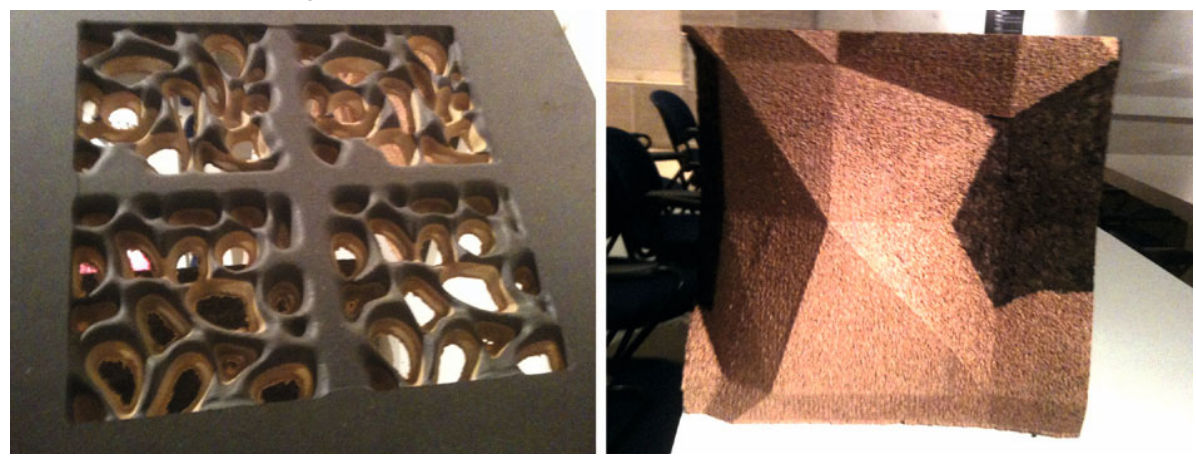

Fig. 5. Examples of panels that demonstrate the influence of the material properties in their final expression. On the left, the colored layers of the Valchromat sandwich add a kind of topographic effect to the intricate perforations. On the right, a custom made sandwich of compound and pure cork agglomerates showing transitions in material color that are not "designed" in CAD files

On the one hand, there are works where fabrication was simply a way to translate a CAD geometry into a physical element. In this case, fabrication parameters and the homogeneity of the raw material did not influence the final result. Indeed, everything was thought, decided and prescribed in the CAD file. On the other hand, there are others that reveal a more holistic approach to digital production. In these works, it is clear how the three factors described above (i.e., design, machining and material parameters) were explored together, to conceive and produce a specific material effect in the end (fig. 6).
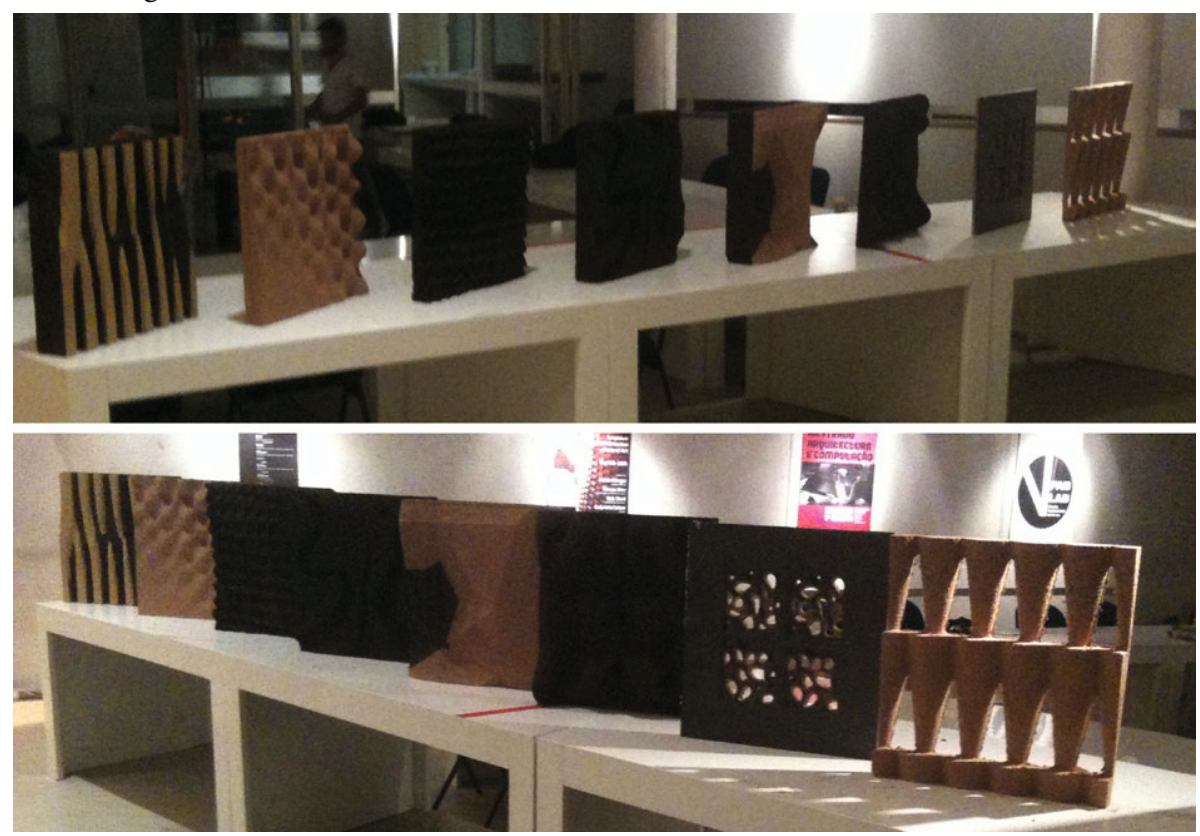

Fig. 6. An overview of the panels produced during this short workshop on digital fabrication 
The impact of this workshop initiative can eventually be understood at three levels. First, together with the Symposium talks, it was an effort to help the organizers in motivating the academic community to adopt such technologies in the school. At the same time, the experience allowed the participants not only to acquire practical skills in $\mathrm{CNC}$ milling processes, but also to develop a critical understanding about the impact of digital fabrication at the formal, material and methodological levels in architecture. For instance, it clearly showed the importance of exploring feedback loops between design and fabrication information to support creative decisions, and the possibility to engage with non-standard modes of production in architecture. Finally, the workshop could be seen as an experience for industrial inspiration. The work produced can serve as an invitation for the material companies that supported the workshop to incorporate a higher degree of customization in their commercial products and production processes by means of digital fabrication technologies.

\section{Acknowledgments}

The author wants to thank Luís de Sousa for his precious help in assisting the students, Rui Salgueiro from Ouplan for his tireless and efficient collaboration with the CNC milling work, to Amorim and Investwood for supporting this workshop with their interesting materials. A final word to thank the organizers for the invitation and support, and to the participants for their curiosity and efforts during the workshop.

\section{Notes}

1. Branko Kolarevic's Architecture in the Digital age. Design and Manufacturing [2003] was mentioned as a clear source of references about the innovative aspects arising from the use of digital technologies in architectural practice.

2. A detailed analysis of cork and the emergent digital possibilities for its application in architecture can be found in my Ph.D. dissertation [Sousa 2010].

3. Exploring the use of CAD/CAM technologies, Bernad Cache and his partner Patrice Beaucé have produced, among other projects, several wooden panels with customized surface and texture effects driven by geometric principles. Their book Objectile [2007] shows some of these works and presents an important critical reflection about the possibility for digital variation in the design and manufacturing of architecture.

\section{References}

BeaucÉ, Patrick and Bernard CaCHe. 2007. Objectile. Fast-Wood: A Brouillon Project. New York: SpringerWien.

Kolarevic, Branko. 2003. Architecture in the Digital Age: Design and Manufacturing. New York: Spon Press.

SoUSA, José Pedro. 2010. From Digital to Material. Rethinking Cork in Architecture through the use of CAD/CAM technologies. Ph.D. dissertation. Instituto Superior Técnico, Technical University of Lisbon.

\section{About the author}

José Pedro Sousa is Professor at FAUP (Porto) and a Guest Professor at dARQ/FCTUC (Coimbra), teaching courses on geometry, computation and digital project. After graduating in Architecture at the FAUP (Porto), he earned a Master degree in Genetic Architectures from the ESARQ-UIC (Barcelona) and a Ph.D. in Architecture from the IST-UTL (Lisbon). Interested in exploring new conceptual and material opportunities emerging from the use of computational design and fabrication technologies, he has developed an intense activity merging research, teaching and design practice in architecture. More information can be found on his website, www.jpsousa.net. 